7. Reprod. Fert. (1937) 13, 173-174

BRIEF COMMUNICATION

\title{
EFFECTS OF MEDROXYPROGESTERONE ACETATE AND OF ETHINYL OESTRADIOL ON THE FERTILIZATION AND TRANSPORTATION OF FERRET EGGS
}

\author{
M. C. CHANG \\ Worcester Foundation for Experimental Biology, \\ Shrewsbury, Massachusetts, U.S.A.
}

(Received 26th August 1966)

The interruption of early pregnancy in the rabbit by oral administration of ethinyl oestradiol (EE) has been reported by Parkes, Dodds \& Nobles (1938). Recent work by Chang \& Harper (1966) has shown that rabbits fed with various oestrogens, especially EE, 1 to 3 days after insemination will induce the degeneration of blastocysts and that the effect is due to the rapid transport of eggs from the tube to the uterus and their expulsion from the uterus. Chang (1966) has further reported that administration of an orally effective progestin, medroxyprogesterone acetate (MPA, Upjohn Company), for 3 days before ovulation has an effect similar to that observed following the administration of oestrogen after ovulation in the rabbit. This communication describes an experiment concerning the fertilization and transport of ferret eggs following oral administration of MPA before ovulation, or of EE given after ovulation.

During July and August, nine mature oestrous ferrets were fed $2 \mathrm{mg}$ MPA in cottonseed oil daily for 3 days before an intraperitoneal injection of 90 i.u. HCG was given to induce ovulation. Uterine insemination of epididymal spermatozoa (Day 0) (Chang, 1965) was performed either at the time of injection of HCG or $12 \mathrm{hr}$ later. Five other animals were fed $0.1 \mathrm{mg}$ EE in cottonseed oil daily for 3 days after ovulation. Five control animals were fed cottonseed oil alone either before or after ovulation. All were killed on Day 4 and their tubes and uterine horns were flushed for the recovery of eggs. The eggs were mounted and examined by phase-contrast microscopy before and after fixation and staining (Chang, 1965). At this time the fertilized eggs were naked and at six- to eight-cell stages. The unfertilized eggs recovered from either the tube or the uterus were still surrounded with corona radiata and some of them had cleaved parthenogenetically into two to four cells.

Of the nineteen females, one (MPA-treated) had pyometra and one each of the EE-treated and control groups failed to ovulate. The results below refer to the remaining sixteen ferrets. Sixty-four eggs were recovered from eight ferrets fed MPA before ovulation. All ferrets had uterine eggs and forty-nine 
$(77 \%)$ of the recovered eggs were in the uterus but only one $(1.6 \%)$ was fertilized. Of forty eggs recovered from four ferrets fed EE after ovulation, none had reached the uterus and twenty-five $(63 \%)$ were fertilized. Of forty-three eggs recovered from four control animals twenty-nine $(68 \%)$ were fertilized. In only one animal had eggs reached the uterus.

Another four animals in each treatment group were examined 13 to 18 days after insemination. No embryo was found in the MPA-treated animals, three embryos were found in the EE-treated animals and twenty embryos were found in the control animals.

Obviously the administration of medroxyprogesterone acetate before ovulation inhibited fertilization and hastened the transport of eggs from the tube to the uterus. Administration of EE after ovulation, however, had no effect on fertilization and egg transport but adversely affected embryonic survival.

The interval between the injection of gonadotrophin and ovulation (about $30 \mathrm{hr}$ ) is the same as the 'mating to ovulation' interval (McPhail, 1933; Chang, 1965). In the ferret, eggs reach the uterus about 6 days after mating (Robinson, 1918). In the present study most of the eggs had reached the uterus in the MPA-treated animals 4 to $4 \frac{1}{2}$ days after the ovulating injection of HCG. It is known that oral administration of oestradiol cyclopentylpropionate or oestrone ( $1 \mathrm{mg} / \mathrm{rabbit}$ ) accelerates egg transport in the rabbit (Chang \& Yanagimachi, 1965) and that oral administration of EE $(0.05$ to $0.1 \mathrm{mg} / \mathrm{rabbit})$ induces complete degeneration of eggs in the rabbit (Chang \& Harper, 1966). Considering the relative body weights of the rabbit $(3500 \mathrm{~g})$ and ferret $(650 \mathrm{~g})$, it seems that the mechanism of egg transport in the ferret is relatively less sensitive to the effects of oestrogen than it is in the rabbit. Fertilization in the rabbit is not inhibited by administration of MPA before ovulation (Chang, 1966). The cause of failure of fertilization in the MPA-treated ferrets could be due to the inhibition of capacitation of spermatozoa in the uterus by progesterone as shown in the rabbit (Chang, 1958) or to disturbances in spermatozoal and egg transport.

This study was supported by a Grant (GM-10529), and a Career Award (K6-HD-18, 334) from U.S.P.H.S. Sincere thanks are due to Miss Nancy Mitchell for assistance.

\section{REFERENCES}

Chang, M. C. (1958) Capacitation of rabbit spermatozoa in the uterus with special reference to the reproductive phase of the female. Endocrinology, 63, 619 .

Chang, M. C. (1965) Fertilizing life of ferret sperm in the female tract. F. exp. Zool. 158, 87.

Chang, M. C. (1966) Effects of oral administration of medroxyprogesterone acetate and ethinyl estradiol on the transportation and development of rabbit eggs. Endocrinology, (In press.)

Chang, M. C. \& HARPER, M. J. K. (1966) Effects of ethinyl estradiol on egg transport and development in the rabbit. Endocrinology, 78, 680

Chang, M. G. \& Yanagimachi, R. (1965) Effects of estrogen and other compounds as oral antifertility agents on the development of rabbit ova and hamster embryos. Fert. Steril. 16, 281.

McPhail, M. K. (1933) Induction of ovulation in the unmated oestrous ferret. F. Physiol., Lond. 80, 78.

Parkes, A. S., Dodds, E. C. \& Nobles, R. L. (1938) Interruption of early pregnancy by means of orally active oestrogens. Brit. med. F. ii, 577.

Robinson, A. (1918) The formation, rupture, and closure of ovarian follicles in ferret and ferretpolecat hybrids, and some associated phenomena. Trans. R. Soc. Edinb. 52, 303. 